\title{
The protective effect of intranasal immunization with inactivated influenza virus vaccine
}

\author{
K. S. LIEM* \\ M.D. \\ J. JACOBS $\dagger$
}

\author{
E. A. Marcus* \\ M.D. \\ R. VAN STRIK $\ddagger$
}

N. V. Philips-Duphar, P.O. Box 2, Weesp, The Netherlands

\begin{abstract}
Summary
Protection against influenza after killed influenza spray vaccine was assessed in nine double blind, placebocontrolled clinical trials and two field studies, involving a total number of 10,000 subjects.

Monovalent vaccine, containing 300-360 IU A/Hong Kong/1/68 (H3N2) or bivalent vaccine, containing 300-360 IU A/Aichi/2/68 (H3N2) and 200-240 IU B/Mass/3/66 per dose was used.

Administration by the intranasal route appeared to be acceptable as an alternative to the parenteral route. The protective efficacy found was comparable with that attained after parenteral vaccination. It has, however, the advantages of a characteristic lack of side-effects and of the fact that no injection is involved. This will probably enhance the acceptance of influenza immunization by the population and thus lead to a higher vaccination rate in the communities we want to protect against influenza.
\end{abstract}

\section{Introduction}

The possibility that local mechanisms in the respiratory tract might play a significant role in the prevention of influenza was first suggested by Francis (1940). Ten years later Fazekas de St Groth \& Donnelly (1950) demonstrated that in mice, protection against influenza correlated better with local than with serum antibodies and that these secretory antibodies could be efficiently stimulated by local application of the antigen.

It would, therefore, seem a logical approach to induce immunity against influenza in man by the respiratory route. Przesmycki, Sawicki \& Dobrowolska (1959) reported favourable results from a series of field studies involving several thousands of subjects with intranasally administered polyvalent inactivated influenza virus vaccines. However, it was not until Tomasi et al. (1965) showed that the

* Clinical Research Department

+ Department of Human Vaccines

$\ddagger$ Statistical Department secretory antibodies belong to a different class of immunoglobulins ( $\operatorname{IgA})$, before interest in practical application of local stimulation of secretory antibodies was revived.

Waldman et al. (1968) and Kasel et al. (1969) demonstrated that direct application to the upper respiratory tract of inactivated influenza virus vaccine resulted in production of local IgA virus neutralizing antibodies. Encouraged by these results, the first field studies with killed influenza virus vaccine given by inhalation were executed in 1967-68 by Waldman, Mann \& Small (1969). The protective efficacy of intranasal vaccination with killed influenza virus vaccine found in these studies was further confirmed by successive double blind studies by Waldman et al. (1969) and by Waldman \& Coggins (1972).

Others, like Edmondson et al. (1971) and Tyrrell et al. (1970), were not able to demonstrate the protective efficacy after intranasal killed influenza vaccine. In the field studies published in the literature the vaccine was administered by means of a coarse hand spray or as nose drops. It is conceivable that these inaccurate methods of administration are partly responsible for the variability in protection rate found in the different trials.

\section{Materials and methods}

The vaccine used was either a monovalent or a bivalent freeze-dried inactivated influenza virus vaccine. The monovalent vaccine contained 300-360 IU A Hong Kong/1/68 (H3N2) per dose; the bivalent vaccine contained $300-360$ IU A Aichi/2/68 (H3N2) and 200-240 IU B Mass/3/66 per dose. The vaccine was administered as a spray using a freonpropelled metered dose aerosol device. This device has been thoroughly tested and extensively used in other fields of medical practice and guaranteed the reproducibility of the grade of dispersion as well as the amount of antigen delivered with each puff. A 
disposable plastic nose and mouth adaptor was fitted on the aerosol device and discarded after each individual vaccination (Fig. 1). One dose of the vaccine corresponded to four puffs. The vaccine was administered during deep inhalation, either given as one puff in each nostril (Fig. 2) and two in the oropharynx (' $2 \times$ nose $+2 \times$ mouth') or as two puffs in each nostril (' $4 \times$ nose').

Stability tests showed that at room temperature the antigenicity of the vaccine was well preserved for at least 18 months.

All studies were placebo-controlled and, with the exception of the Reading study where variable doses and different routes of administration were tested, double blind. Allocation to the active vaccine or the placebo aerosol was done according to a predetermined randomization scheme. A summary of the trials is given in Table 1.

The Reading trial was primarily set up as a tolerance study and as an investigation into the immunologic response. In the South African trials (5a-d) a group consisting of an equal number of subjects were included who received parenteral vaccine. Half of the subjects of the groups who received the vaccine were given a booster immunization 4 weeks after the first one; the remaining subjects received placebo spray at the same time.

The systemic antibody responses were studied from serum samples taken from all volunteers (Reading) or from each fortieth subject (South African trials). Specific antibodies against the A2 Hong Kong strain were determined as haemagglu-

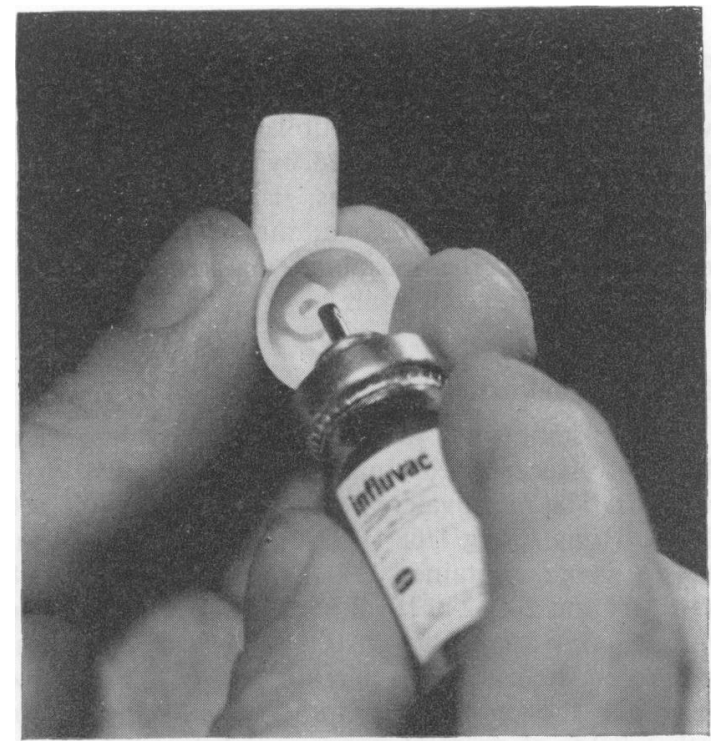

FIG. i. Aluminium vial containing freeze-dried vaccine and disposable adaptor.

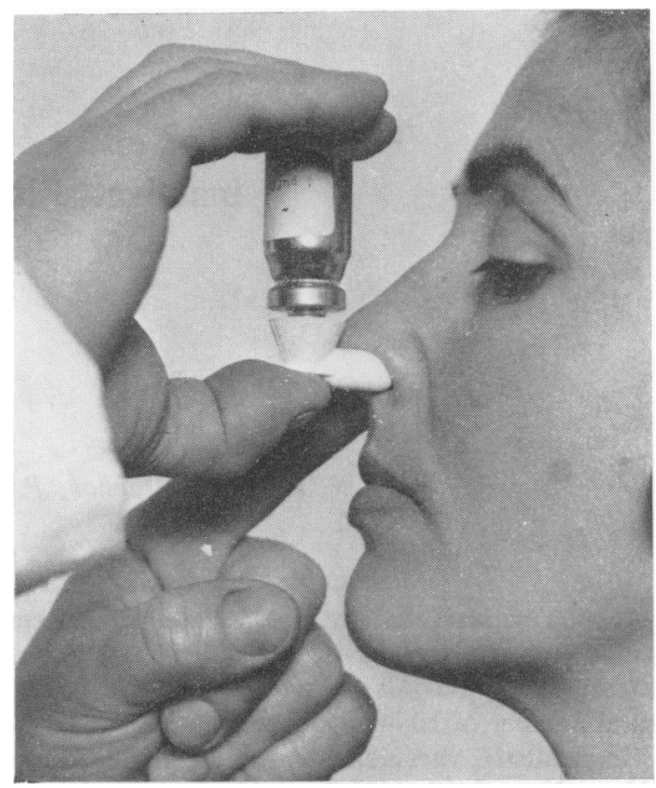

FIG. 2. Vaccination by intranasal inhalation.

tination-inhibition antibodies in sera taken before and 4 weeks after vaccination. In the Reading exo periment the postvaccination samples were taken and 10 weeks after immunization. In the Naples study nasal washes were taken from each twentietff subject before and 4 weeks after vaccination.

Local antibodies were determined as specific neutralizing antibody titres found in the nasal wash $\stackrel{\mathbb{Q}}{\mathscr{Q}}$ samples.

All cases of acute respiratory disease which occurred among the studied population between the day of vaccination and the end of the influenza epidemic season were recorded. Blood samples were taken from them at the onset of the disease and 33 weeks thereafter.

Attack rates were exclusively based on the serologically confirmed cases of influenza, i.e. four-fold $\delta$ rise in $\mathrm{CF}$ and/or HI titres between first day sera and convalescence sera taken 3 weeks after the onset of 윽 the illness.

Except in the Reading and Zagreb studies where this $\frac{D}{2}$ was not feasible, serological confirmation of influenza was based on four-fold increase in CF titres $\sigma$ between prevaccination and postepidemic sera. In $\cong$ most of the Reading sera the CF titres could not be determined due to anticomplement activity; therefore, the agar gel precipitation test (AGP test) has been used instead (Beard, 1970).

Two additional field studies were executed in the \& United Kingdom under the auspices of Riker $\square$ Laboratories among factory workers of British Leyland and Unilever Ltd. In these studies spray vaccine $\stackrel{\square}{\Omega}$ 
TABLE 1. Summary of trials

\begin{tabular}{lclcll}
\hline & Season & Centre & No. of subjects & $\begin{array}{c}\text { Vaccine } \\
\text { composition }\end{array}$ & $\begin{array}{c}\text { Route of } \\
\text { administration }\end{array}$ \\
\hline 1. & $1969 / 70$ & Reading & 66 & Monovalent & Different routes \\
2. & $1969 / 70$ & Naples & 500 & Monovalent & $2 \times$ nose $+2 \times$ mouth \\
3. & $1969 / 70$ & Zagreb & 2000 & Bivalent & $2 \times$ nose $+2 \times$ mouth \\
4. & $1969 / 70$ & Lierneux I & 520 & Bivalent & $2 \times$ nose $+2 \times$ mouth \\
5a. & 1970 & Johannesburg & 1500 & Bivalent & $4 \times$ nose \\
5b. & 1970 & Johannesburg & 1500 & Bivalent & $2 \times$ nose $+2 \times$ mouth \\
5c. & 1970 & Pretoria & 1500 & Bivalent & $4 \times$ nose \\
5d. & 1970 & Pretoria & 1500 & Bivalent & $2 \times$ nose $+2 \times$ mouth \\
6. & $1970 / 71$ & Lierneux II & 525 & Bivalent & $4 \times$ nose \\
\hline
\end{tabular}

was offered to those who volunteered for immunization; no placebo could be given under the circumstances. Protection against influenza illness was assessed by comparing the incidence of clinical influenza among the vaccinees with the incidencerate of a group of unvaccinated workers of the same factory matched as to age, sex and occupation.

\section{Results}

\section{Systemic antibody response}

The response in serum antibodies after intranasal vaccination was found to be very low. Excluding the subjects who had had an attack of influenza, the fold increase in geometric mean $\mathrm{HI}$ antibody titres between pre- and 4 weeks post-vaccination sera from the Reading trial was only 1.73 (number of sera tested $45 ; 95 \%$ confidence limits: $1 \cdot 36-2 \cdot 20)$. This was comparable with the fold increase in serum $\mathrm{HI}$ antibodies found in the samples from the South African trials (Table 2).

The local antibody response studied from nasal washes taken before and after vaccination showed a slight increase in titres after intranasal vaccination (Table 3).

\section{Protective effect}

The attack-rates for influenza among our study population were very low. In the season 1969/70 a fairly high attack rate of A2 Hong Kong influenza was reported in most Western European countries.
TABLE 2. Fold increase of geometric mean serum HI antibody titres after vaccination excluding the patients who had clinical influenza (combined South African trials)

\begin{tabular}{ccc}
\hline $\begin{array}{c}\text { No. of sera } \\
\text { tested }\end{array}$ & $\begin{array}{c}\text { Fold increase } \\
(95 \% \text { confidence limits })\end{array}$ & $\begin{array}{c}\text { Route of } \\
\text { application }\end{array}$ \\
\hline 37 & $4 \cdot 63(3 \cdot 16-6 \cdot 76)$ & Subcutaneous \\
66 & $1 \cdot 84(1 \cdot 37-2 \cdot 46)$ & $4 \times$ nose \\
72 & $1 \cdot 43(1 \cdot 17-1 \cdot 77)$ & $2 \times$ nose \\
& & $2 \times$ mouth \\
115 & $1 \cdot 10(0 \cdot 92-1 \cdot 32)$ & Placebo \\
\hline
\end{tabular}

The epidemic, however, started at an unexpectedly early date (first week of December) and therefore, the vaccination procedure was started too late in both the Naples and Zagreb trials. In Zagreb the epidemic outbreak coincided with the start of our vaccination programme. In Naples the epidemic reached its peak when we started the immunization. Nevertheless, we have attempted to assess the protective effect of the vaccination by disregarding the cases of influenza illness which occurred in the first 2 weeks following vaccination.

In 1970 a fairly high attack rate of A2 Hong Kong influenza was also reported in South Africa. However, in our studies the incidence of influenza illness was disappointingly low. The studies were carried out in rather isolated communities and the low attack-rate could be due to a 'herd immunity' induced by the high vaccination rate as a result of our immunization schedule. Table 4 shows the combined figures on the incidence of serologically con-

TABLE 3. Fold increase in virus-neutralizing antibody titres between pre- and post-vaccination samples as nasal washes

\begin{tabular}{llcc}
\hline Centre & & $\begin{array}{c}\text { No. of } \\
\text { samples } \\
\text { tested }\end{array}$ & $\begin{array}{c}\text { Mean geometric } \\
\text { fold increase } \\
(95 \% \text { confidence limits })\end{array}$ \\
\hline \multirow{3}{*}{ Reading* } & $\begin{array}{l}\text { Non-vaccinated } \\
\text { Naples } \dagger\end{array}$ & 23 & $1 \cdot 09(0 \cdot 95-1 \cdot 15)$ \\
& Saccinated & 23 & $1 \cdot 39(1 \cdot 10-1 \cdot 76)$ \\
& Subjects with influenza & 11 & $2 \cdot 12(1 \cdot 21-3 \cdot 72)$ \\
& Alacebo & 7 & $1 \cdot 22(0.50-2 \cdot 94)$ \\
\hline
\end{tabular}

* Postvaccination samples taken 6 weeks after immunization.

† Postvaccination samples taken 4 weeks after immunization. 
TABLE 4. Combined figures on the incidence of serologically confirmed cases of influenza (four-fold rise in CF titres) in the South African trials

\begin{tabular}{cccc}
\hline \multicolumn{1}{c}{ Route } & \multicolumn{3}{c}{ Vaccination schedule } \\
\cline { 2 - 4 } & $\begin{array}{c}\text { Active vaccine } \\
\text { with booster }\end{array}$ & $\begin{array}{c}\text { Active vaccine } \\
\text { without booster }\end{array}$ & Placebo \\
\hline $\begin{array}{l}\text { Subcutaneous } \\
\text { Spray } 4 \text { nose }\end{array}$ & $0^{*}$ & 3 & 5 \\
$\begin{array}{c}\text { Spray } 2 \text { nose } \\
+2 \text { mouth }\end{array}$ & 2 & $1^{*}$ & 7 \\
\hline
\end{tabular}

* Values differ significantly $(P<0 \cdot 05)$ from placebo value.

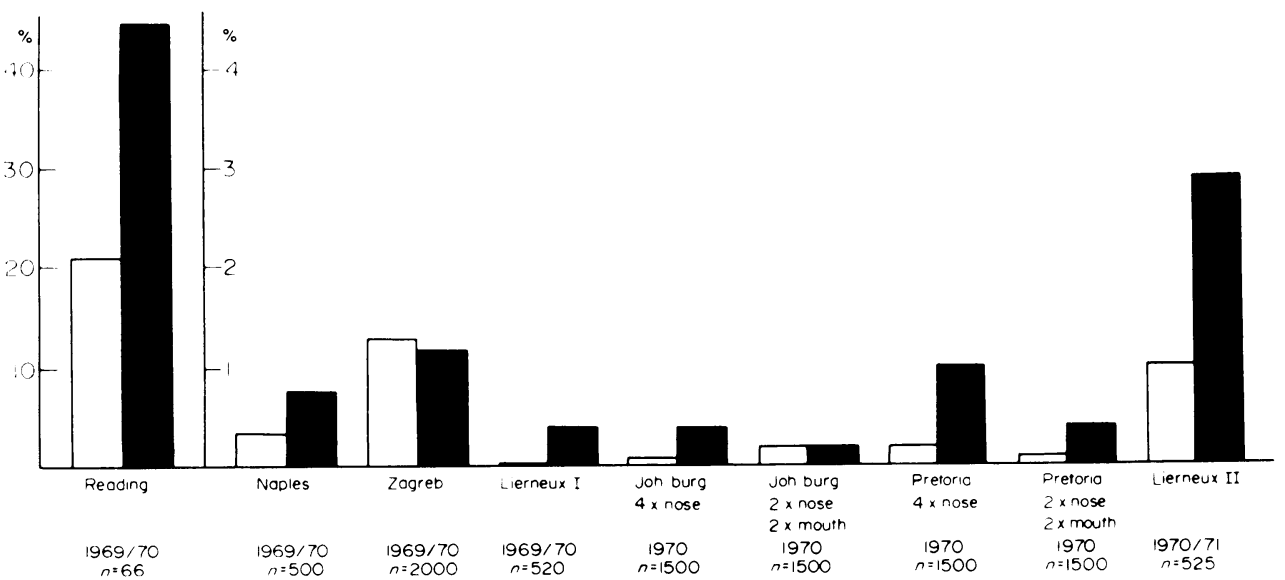

Fic. 3. Summary of results of nine placebo-controlled field trials with influenza spray vaccine. Open columns, active; closed columns, placebo. (Attack rates expressed as a percentage of total numbers of subjects in each group.)

firmed cases of A2 influenza of the South African trials.

The attack-rates for influenza found in all nine studies are depicted in Fig. 3. Protection-rate was calculated from the numbers of serologically confirmed influenza cases among the studied population and expressed as the percentage reduction in the influenza incidence among the vaccinees as compared with the placebo group.

Due to the low incidence of influenza, the difference between the attack-rates among the vaccinated groups and placebo controls for each individual trial was not statistically significant. However, the same positive trend towards protection from the vaccine was repeatedly found. A weighted average of the protection-rates derived from the reported percentages of infection in the various trials was calculated and was found to be $58 \%$ (statistical significance $P=0.04$ ).

If the results of the Naples and Zagreb trials were excluded because the immunization was given when the epidemic had already started, the average protection rate was found to be $69 \%(P-0.02)$. If one would exclude the Reading and Zagreb trials because the trial set up for these two studies was somewhat different from that in the others, the average of protection-rates was even found to be $74 \%(P=0.02)$ (see Table 5).

TABLE 5. Average protection rates

\begin{tabular}{|c|c|c|}
\hline & Protection & $P$ \\
\hline All nine trials & $58^{\circ}$ & $0 \cdot 04$ \\
\hline $\begin{array}{l}\text { Zagreb and Naples } \\
\text { excluded }\end{array}$ & $69^{\circ}$, & 0.02 \\
\hline $\begin{array}{l}\text { Reading and Zagreb } \\
\text { excluded }\end{array}$ & $74 \%$ & 0.02 \\
\hline
\end{tabular}

TABı.. 6. Incidence of clinical influenza (British Leyland, Unilever) $1970-71$

\begin{tabular}{|c|c|c|}
\hline & Vaccinated & Control: \\
\hline $\begin{array}{l}\text { British Leyland } \\
\text { Number } \\
\text { Attack rate }\left({ }^{\circ}, n\right)\end{array}$ & $\begin{array}{c}1.330 \\
0.8\end{array}$ & $\begin{array}{r}650 \\
1.6\end{array}$ \\
\hline $\begin{array}{l}\text { Unilever Ltd } \\
\text { Number } \\
\text { Attack rates whole winter }\left({ }^{\circ}, 0\right) \\
\text { Attack rates January peak } 71^{\prime \prime}\left({ }^{\prime}, 0\right)\end{array}$ & $\begin{array}{l}483 \\
2 \cdot 5 \\
0 \cdot 6\end{array}$ & $\begin{array}{l}483 \\
6 \cdot 2 \\
3 \cdot 5\end{array}$ \\
\hline
\end{tabular}


In the 1970/71 Lierneux II (trial no. 6) study, the influenza outbreak was caused by a $B$ strain. The epidemic occurred in April 1971, 5 months after the immunization which took place in November 1970 .

The results of the two field studies executed under the auspices of Riker laboratories are shown in Table 6.

\section{Side-effects}

The spray vaccination was characteristically devoid of side-effects. Except for a transient cough in some subjects immediately after vaccination, no sideeffects, neither systemic nor local, have been noted. In the tolerance studies in Reading, peak flow values were recorded before and $30 \mathrm{~min}$ after the spray vaccination; no change in airway resistance was found.

The general acceptance of the vaccination by spray by the subjects who participated in the trials was extremely favourable. Particularly the intranasal route was very well accepted.

\section{Discussion}

Our results on the immunologic response after intranasal vaccination are in agreement with those reported by previous investigators (Waldman et al., 1968). The seroconversion rate after spray vaccine was very low. Nasal antibody response was found to be more marked and consistent. The determination of the local antibodies was done in the unconcentrated nasal wash samples; for this reason we must have missed some of the smaller responses. In a later investigation, where local antibody responses after nasal spray and subcutaneous vaccine were compared, we used concentrated nasal washings. With the increased sensitivity of secretory antibody determination, a higher response was found (to be published later).

The combined results of the double blind trials present statistically significant evidence for the protective effect of the vaccine given by inhalation. Two other field studies reported in this paper give further support to our conclusion that the protection after intranasal spray vaccine seems comparable with that attained after parenteral vaccine.

\section{Conclusion}

The intranasal vaccination with killed influenza virus vaccine seems an acceptable alternative route of immunization against influenza. The protective effect is found to be comparable with that attained after parenteral vaccine. The intranasal route gives negligible side-effects. This lack of systemic or local reaction to the intranasal vaccine may enhance its acceptance by the public.

\section{Acknowledgments}

We would like to thank all colleagues in the different centres who made the studies possible for their valuable contribution in the execution of the trials. We are indebted to Miss J. E. Truin for her technical assistance in the preparation of the studies.

\section{References}

BEARD, C.W. (1970) Demonstration of type specific influenza antibody in mammalian and avian sera by immunodiffusion. Bulletin of the World Health Organization, 42, 779.

Edmondson, W.P., Rothenberg, R., White, P.W. \& GWALTNEY, J.M. (1971) A comparison of subcutaneous, nasal, and combined influenza vaccination. II. Protection against natural challenge. American Journal of Epidemio$\log y, 93,480$.

Fazekas de St Groth, S. \& Donnelley, M. (1950) Studies in experimental immunology of influenza IV. Australian Journal of Experimental Biology and Medical Science, 28, 61.

Francis, T. (1940) The inactivation of epidemic influenza virus by nasal secretions of human individuals. Science, 91 , 198.

Kasel, J.A., Hume, E.B., Fulk, R.V., Togo, Y., Huber, M. \& HoRNICK, R.B. (1969) Antibody responses in nasal secretions and serum of elderly persons following local or parenteral administration of inactivated influenza virus vaccine. Journal of Immunology, 102, 555.

Przesmycki, F., Sawicki, L. \& Dobrowolska, H. (1959) Vaccination against influenza in Poland 1953-56. Bulletin of the World Health Organization, 20, 333.

Tomasi, T.B., Tan, E.M., Solomon, A. \& Prendergast, A. (1965) Characteristics of an immune system common to certain external secretions. Journal of Experimental Medicine, 121, 101.

Tyrrell, D.A.J., Buckland, R., Rubenstein, D. \& Sharpe, D.M. (1970) Vaccination against Hong Kong influenza in Britain 1968-69. Journal of Hygiene, 68, 359.

Waldman, R.H., Kasel, J.A., FulK, R.V., Togo, Y., Hornick, R.B., Hemer, G.G. \& Dawkins, A.I. (1968) Influenza antibody in human respiratory secretions after subcutaneous or respiratory immunization with inactivated virus. Nature, 218, 594.

Waldman, R.H., ManN J.J. \& Small, P.A. (1969) Immunization against influenza. Journal of American Medicine, 207, 520.

WALDMAN, R.H., Bond, J.O., LeVITT, L.P., HaRTWIG, E.C., Prather, E.C., Baratta, R.L., Neill, J.S. \& Small, P.A. (1969) An evaluation of influenza immunization. Bulletin of the World Health Organization, 41, 543.

Waldman, R.H. \& CogGins, W.J. (1972) Influenza immunization: Field trial on a university campus. Journal of Infectious Diseases, 126, 242. 